\title{
Corrigendum: Editorial: Reliability and Reproducibility in Functional Connectomics
}

\section{OPEN ACCESS}

Approved by:

Frontiers in Neuroscience Editorial Office,

Frontiers Media SA, Switzerland

${ }^{*}$ Correspondence:

Xi-Nian Zuo

zuoxn@gxtc.edu.cn;

zuoxn@psych.ac.cn

Specialty section:

This article was submitted to Brain Imaging Methods, a section of the journal Frontiers in Neuroscience

Received: 17 March 2019 Accepted: 01 April 2019 Published: 16 April 2019

Citation:

Zuo X-N, Biswal BB and Poldrack RA (2019) Corrigendum: Editorial: Reliability and Reproducibility in

Functional Connectomics.

Front. Neurosci. 13:374. doi: 10.3389/fnins.2019.00374

\begin{abstract}
Xi-Nian Zuo ${ }^{1,2,3,4,5,6 *}$, Bharat B. Biswal ${ }^{7,8}$ and Russell A. Poldrack ${ }^{9}$
${ }^{1}$ Key Laboratory of Brain and Education, Nanning Normal University, Nanning, China, ${ }^{2}$ Department of Psychology, University of Chinese Academy of Science, Beijing, China, ${ }^{3}$ CAS Key Laboratory of Behavioral Sciences, Institute of Psychology, Beijing, China, ${ }^{4}$ Magnetic Resonance Imaging Research Center, CAS Institute of Psychology, Beijing, China, ${ }^{5}$ Research Center for Lifespan Development of Mind and Brain, CAS Institute of Psychology, Beijing, China, ${ }^{6}$ Institute for Brain Research and Rehabilitation, South China Normal University, Guangzhou, China, ${ }^{7}$ The Clinical Hospital of Chengdu Brain Science Institute, MOE Key Lab for Neuroinformation, University of Electronic Science and Technology of China, Chengdu, China, ${ }^{8}$ Department of Biomedical Engineering, New Jersey Institute of Technology, Newark, NJ, United States, ${ }^{9}$ Department of Psychology, Stanford University, Stanford, CA, United States
\end{abstract}

Keywords: test-retest reliability, functional connectomics, open science, dynamic brain theory, big data

\section{A Corrigendum on}

Editorial: Reliability and Reproducibility in Functional Connectomics

by Zuo, X.-N., Biswal, B. B., and Poldrack, R. A. (2019). Front. Neurosci. 13:117. doi: 10.3389/fnins.2019.00117

In the original article, we neglected to include the funder "Guangxi BaGui Scholarship, 201621" to X-NZ.

In the published article, there was an error regarding the affiliation for Bharat Biswal. As well as having affiliation 8, he should also have "The Clinical Hospital of Chengdu Brain Science Institute, MOE Key Lab for Neuroinformation, University of Electronic Science and Technology of China, Chengdu, China."

The authors apologize for this error and state that this does not change the scientific conclusions of the article in any way. The original article has been updated.

Copyright (๑) 2019 Zuo, Biswal and Poldrack. This is an open-access article distributed under the terms of the Creative Commons Attribution License (CC BY). The use, distribution or reproduction in other forums is permitted, provided the original author(s) and the copyright owner(s) are credited and that the original publication in this journal is cited, in accordance with accepted academic practice. No use, distribution or reproduction is permitted which does not comply with these terms. 